\title{
The role of scale structure in the interpretation of contrariety in no-DPs
}

\author{
Rachel Szekely*
}

\begin{abstract}
Contrary meaning is commonly analyzed as a pragmatic strengthening of contradictory sentence negation. This paper derives the contrary meaning found in no-DPs in predicate position (e.g. "John is no fool") through the analysis of no as negation that operates on the scale contributed by the predicate nominal expression.
\end{abstract}

Keywords. Negation, contrariety, scalar meaning, prototypicality, noun phrase interpretation, pragmatics, semantics

1. Introduction. The sentences $I t$ is raining and It is not raining stand in contradictory opposition - in any context of use, if one of them is true the other is false, and that exhausts the possibilities. Sentences like John is happy and John is sad, on the other hand are opposed in a different way. These two sentences cannot be true together but can both be false, and together they do not exhaust the possibilities, because John may be neither happy nor sad. In other words, the first pair of sentences but not the second is subject to the Law of Excluded Middle. Current research on negation treats contradictory opposition as basic and derives contrary opposition pragmatically from it. More specifically, contrary opposition is analyzed as the pragmatic strengthening of a contradictory sentential negation through logical inferences, notably the Disjunctive Syllogism, which I review to below (see, for example, Horn and Wansing 2016, section 1.6). In what follows I make the case for a different account of contrary meaning in noDP predicates, which appeals to the interaction of negation with nominal scale structure, leaving open the possibility that the inferential approach explains other phenomena such as neg-raising and the interpretation of predicative adjectives.

2. The meaning of no. Many recent analyses of determiner no take it to contribute or require sentential negation. Some translate $n o$ as a sentential negation plus an indefinite (e.g. Collins and Postal 2014, Zanuttini 1991/1997) and others as a non-negative indefinite that is required to be in the scope of sentence negation (e.g. Ladusaw 1992, Penka 2010, Zeijlstra 2004). While different in detail, these analyses translate both 1 and 2 into sentences containing a sentential negation and an indefinite.

(1) John isn't a fool.

(2) John is no fool.

'It is not the case that John is a fool.'

But, the use and interpretation of 1 and 2 differ in a number of ways that are unexpected on a uniform analysis of the two sentence types. Notably, sentence 2 is commonly used to express the contrary-We use 2 to mean not just that John is not a fool, as in 1, but that John is the opposite of a fool, that he is clever or shrewd. Sentence 1 is not commonly used with this meaning.

Let me highlight some other differences between the two sentence types. First of all, the copular sentence with sentential negation is used when its affirmative counterpart is either explicitly or by inference available in the context. The structure containing the no-DP does not necessarily have this relation to its affirmative counterpart. This is illustrated by examples $3-5$,

\footnotetext{
* I would like to thank Robert Fiengo for discussing this material with me on a number of occasions, the participants in Chris Collins' fall 2016 seminar on negation at NYU, who provided feedback on an earlier version of this paper, and Larry Horn for his feedback during and after the session. Authors: Rachel Szekely (rachel.szekely@liu.edu).
} 
taken from the Corpus of Contemporary American English. In both environments, replacing "no fool" with "not a fool" changes the background assumptions against which we evaluate the sentence. This is evident when we add the continuation "as Dave used to claim":

(3) The punch stings my hand, but the pain only serves to focus me. And in that moment of clarity, I realize I've picked up a pool stick, which I swing with gusto. I'm no fool, as Dave used to claim. Nor do I believe in a fair fight.

(4) The punch stings my hand, but the pain only serves to focus me. And in that moment of clarity, I realize I've picked up a pool stick, which I swing with gusto. I'm not a fool, as Dave used to claim. Nor do I believe in a fair fight.

(5) Tabby, as she's known -- was the stand-by-your-man type, a wife who would graciously defer to the dreams of her husband at the expense of her own comfort. That may all be true. But after seeing her with her family, I came away with the strong sense that if she encouraged King to keep going, it was because she was no fool, as Dave used to claim - she had editorial judgment and knew good writing when she saw it.

(6) Tabby, as she's known -- was the stand-by-your-man type, a wife who would graciously defer to the dreams of her husband at the expense of her own comfort. That may all be true. But after seeing her with her family, I came away with the strong sense that if she encouraged King to keep going, it was because she wasn't a fool, as Dave used to claim - she had editorial judgment and knew good writing when she saw it.

In 4 and 6 with sentential not, the continuation "as Dave used to claim" implies that Dave used to claim that $x$ was a fool. In examples 3 and 5, with $n o$, the continuation is also compatible with the background that Dave used to claim that $x$ was no fool. So the copular sentence containing sentential negation depends on a background containing its affirmative counterpart, but the sentence containing the no-DP does not. These examples illustrate the different role played by the sentence types in 1 and 2 in relation to the context of utterance.

Negative sentences are also customarily described as less informative than their positive counterparts. But the structure in 2, with the no-DP predicate, is more informative than 1 in a variety of contexts. Compare the use of these structures in reply to a request to "Tell me about John", in 7. Response B is adequate, showing that despite the presence of negation, " $x$ is no fool" is an informative reply to a request for an " $x$ such that John is $x$ ". The response in B', using " $\mathrm{x}$ is not a fool," is less than a complete answer. We can infer from the answer in B' that although the speaker cannot give us an $x$ such that John is $x$, he is attempting to be cooperative by supplying us at least with an $x$ such that John is not $x$ :
A: Tell me about John.
$\mathrm{B}$ : He is no fool.
$\mathrm{B}^{\prime}$ : He is not a fool.

Finally, while both sentence negation and no-DPs reverse the order of scalar entailments and implicatures of the sentences they appear in, as illustrated in 8-10, the sentence containing sentential negation, results in an overall weaker statement than the sentence containing no-DP, as exemplified in 11 and 12:

(8) John is a fool.

(9) John is not a fool.
Higher value In fact, he is an utter fool. \#In fact, he is an utter fool.
Lower value

\#In fact, he is rather clever.

In fact, he is rather clever. 
(10)
John is no fool.
\#In fact, he is an utter fool.
In fact, he is rather clever.

Overall strength:

(11) John is not a fool; \#In other words, he is rather clever.

(12) John is no fool; In other words, he is rather clever.

Whereas 11, "John is not a fool", is not compatible with the paraphrase "John is rather clever", the sentence "John is no fool" in 12 is strong enough already to be compatible with this paraphrase.

I believe that the differences in these sentences types - their overall strength, informativeness and their relation to preceding discourse, together with the fact that 2 but not 1 conventionally has a contrary meaning, cast doubt on a uniform analysis. Furthermore, as we will see in the next section, the pragmatic approach to the contrary meaning in 2 relies on inferences that ought to be available for both sentence types, but in fact are available to one and not the other.

3. The proposal of Bartsch (1973). Let us turn now to a review of the model of strengthening proposed by Bartsch (1973). Her proposal concerns the strengthened meaning we find in negraising contexts where a matrix negation, as in 13 , can be interpreted with embedded scope, as in 14:

(13) John doesn't believe that it will rain.

(14) John believes that it won't rain.

To account for this strengthening, Bartsch invokes the Disjunctive Syllogism, which I give in 15 . In a sentence containing a propositional attitude verb and a negation, such as 13 , she claims that the assertion that John doesn't believe that $p$ licenses the inference that John believes that not $p$ because, if a speaker "believes" or "wants" or "thinks" that $p$, she is not neutral as to whether $p$ or $\neg$. Consequently, the utterance of "not believe p" always licenses the inference to "believe not p". This reasoning is summarized in 16 for the examples in 13 and 14.

(15) The Disjunctive Syllogism (a.k.a. Modus Tollendo Ponens, polarizing disjunction)

$\mathrm{p \vee q}$

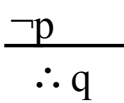

(16) $\mathrm{pVq} \quad$ John believes $\mathrm{p}$ (it is going to rain) OR John believes $\mathrm{q}$ (it is not going to rain)

$\neg \mathrm{p} \quad$ John doesn't believe $\mathrm{p}$ (it is going to rain).

$\therefore \mathrm{q} \quad$ John believes q. (it is not going to rain).

In a number of papers Horn $(1989,2014)$ has extended this schema of pragmatic strengthening to other phenomena, including contrary opposition. So, for example, a copular sentence with an adjectival predicate such as "John isn't nice," is conventionally used to mean that John is mean on this theory because in conversation we tend to extend the schema for disjunctive reasoning holding between contradictory terms to contrary opposites, opposites which then function as if there were an excluded middle. This happens for various reasons including politeness, that is, to avoid saying directly that John is mean. So, although it is possible to be neither nice nor mean, when we use the sentence John isn't nice we exclude these middle possibilities; instead we use nice as a complementary antonym, in doing so collapsing a series of alternatives into a 
disjunction of polar opposites (2014:7). And once the disjunction $p \vee q$ is available in context, the assertion of $\neg p$ will yield the strengthening we saw in the neg-raising cases above, as per the disjunctive syllogism. This is shown schematically in 17:

$\begin{array}{ll}\mathrm{pVq} & \text { John is nice OR John is mean. } \\ \neg \mathrm{p} & \text { John isn't nice. } \\ \therefore \mathrm{q} & \text { John is mean. }\end{array}$

Horn extends this same reasoning to explain the strengthening we find with no-DP predicates such as 2 . However, as mentioned above, given the uniform analysis of 1 and 2, pragmatic strengthening should apply uniformly to both sentence types. We have seen however, that unlike negated copular sentences with predicative adjectives, copular sentences with negated nominal predicates are not conventionally strengthened in this way, while those with no-DP predicates are. The situation is summarized in the table in 18 , which shows that the copular sentence with sentential negation does not strengthen when it ought to according to the Disjunctive Syllogism.

(18) Application of Distjunctive syllogism to 1 and 2:

\begin{tabular}{|l|l|l|l|l|}
\hline $\begin{array}{l}\text { PRAGMATICALLY } \\
\text { ASSUMED } \\
\text { DISJUNCTION }\end{array}$ & $\mathrm{pVq}$ & $\begin{array}{l}\text { Contrary treated as } \\
\text { exhaustive/contradictory. }\end{array}$ & \multicolumn{2}{|l|}{$\begin{array}{l}\text { John is a fool or John is } \\
\text { clever. }\end{array}$} \\
\hline ASSERTION & $\neg \mathrm{p}$ & Utterance of $\neg \mathrm{p}$. & $\begin{array}{l}\text { John isn't a } \\
\text { fool. }\end{array}$ & $\begin{array}{l}\text { John is no } \\
\text { fool. }\end{array}$ \\
\hline $\begin{array}{l}\text { PROPOSITION } \\
\text { CONVEYED }\end{array}$ & $\therefore$ & $\begin{array}{l}\text { Should imply contrary } \\
\text { Cp. }\end{array}$ & $\begin{array}{l}\text { Contradictory } \\
\begin{array}{l}\text { 'It }): \\
\text { 'It not the } \\
\text { case that John } \\
\text { is a fool.' }\end{array}\end{array}$ & $\begin{array}{l}\frac{\text { Contrary }}{(\mathrm{C} p):} \\
\text { 'John is } \\
\text { clever'. }\end{array}$ \\
\hline
\end{tabular}

4. Distribution of contrary meaning in no-DPs. Now, not only does the distribution of contrary meaning with no-DPs contrast with indefinites under the scope of sentential negation, but also, no-DPs have contrary meaning as predicates, but not as arguments. Sentence 19 shows contrary meaning is unavailable for $n o$-DPs as internal arguments, located inside VP:

(19) This class has no fool.

Sentence 19 cannot be used to mean that this class has a clever individual in it; rather, it says that there are no fools in the class. Jespersen (1917: 427) already noticed this asymmetry between subjects and predicates in the availability of contrary meaning - his original examples are given in 20 and 21. In 20 No ordinary boy has a contrary meaning, as a predicate, but it does not have this meaning as an argument, in 21:

(20) John is no ordinary boy.

(21) No ordinary boy hates cricket.

Jespersen distinguishes 20 and 21 in terms of the scope of negation, applying in 20 to the adjective ordinary, producing contrary meaning, and in 21 to the entire nominal. His analysis is silent, however, on why the contrary meaning available in one environment and not the other. 
5. Contrariety and nominal scale structure. The differences between the two sentence types that we've reviewed so far leads me to propose that the role played by negation is different in 1 and 2, and to suggest an alternative explanation for the strengthened meaning we find with no, which I will take to be a negative quantifier that interacts with nominal scale structure in a way that sentential negation does not.

A number of authors have explored the scalar dimensions of nouns, whether or not they also take them to allow degree arguments (such as Morzycki 2011, Sassoon 2007 and Syrett 2016). Some evidence in favor of the idea that nominal predicates are scalar comes from the availability of degree modification predicate position as in John is such a fool and John is an utter/complete fool, as well as exclamative some, which is also restricted to predicate uses, e.g. That is some pig!

Now, consider our original example John is no fool and the fact that being a fool is a property that one can have to varying degrees. I propose we analyze the sentence John is no fool as a predication about the extent of John's being a fool. By using 2 one asserts that John instantiates this property to no degree whatsoever - and if there is no degree to which John instantiates the property, the degree of his being a fool is zero. In this and what follows I am assuming a relationship between negation and quantity that Russell proposed in his (1903) Principles of Mathematics. Russell holds that quantities of any sort can be measured and ordered according to their degree, or magnitude as he calls it, such that every quantity of a given concept has a corresponding magnitude. However, there is no quantity whose magnitude, or degree, is zero - no quantity of any concept whose magnitude is zero exists. So, in Russell's system, the zero degree of any property is introduced indirectly by means of negative quantification over degrees. To take our original example, if there is no degree $d$ such that John is $d$ a fool, then the degree of his being a fool can be said to be zero. From this perspective, the meaning of the sentence John is no fool can be paraphrased in the following way: there is no degree $d$ of the predicate being a fool such that John's being a fool measures $d$.

Although I won't provide a compositional semantics here, at the level of generality I'm speaking the basic ingredients of the analysis are common to a number of approaches to measurement and quantity including those stemming from Kennedy (2007), including especially Stephanie Solt's work (2014/2016). Schematically, let us suppose the predicate 【fool』is scalar; as part of its meaning it denotes a scale $S$ and a set of degrees $D$, an ordering relation $>$ on D and a dimension of measurement DIM. We will see that the dimension of measurement will differ crucially for arguments and predicates. The relevant dimension for predicate nominals is qualitative, that of prototypicality to a typical exemplar (cf. Morzycki 2011, Sassoon 2007), while in arguments it is quantitative, that of number or amount. The scale and its dimension of measurement is encoded by the noun whose members exemplify the property to varying degrees. Following Solt (2014) I take there to be a measurement phrase in constituency with the scalar noun that introduces the measurement function $\mu S$, and propose that $n o$ is a negative quantifier over degrees. Through predication, the measure function $\mu \mathrm{S}$ links degrees to individuals, mapping an individual $x$ to the degree on the scale that represents $x$ 's measure with respect to the dimension. The contribution of no in this environment is to indicate that the degree is zero, again, indirectly, by saying that there is no degree $d$ such that the argument has that degree of the scalar property. 
6. Distinguishing contrary and contradictory meaning. I take it to be possible for an individual to have some degree of prototypicality on a dimension defined by a noun predicate, such as being a fool, yet fail to be a member of the class. That is, there is some degree on the scale of being a fool that is a threshold value for set membership, such that it is possible to be a bit foolish without being able to be truly called a fool. To understand the difference between the contrary John is no fool and the contradictory John is not a fool, consider that on the proposed analysis the meaning of John is no fool precludes even the case in which someone is a fool to some degree less than that required to be a member of the class. By specifying that there is no degree of being a fool $d$ such that John is a $d$ fool, we assert that John has none of the qualities/dimensions typical of a member of the class. Now if even non-fools can be a little bit foolish, an individual that is said to be no fool at all might be said to be clever or shrewd - the opposite of a fool. This is, informally, how I propose to distinguish the contrary meaning of 2 and the contradictory meaning in 1, seen in the paraphrases in 22 and 23:

(22) John is not a fool. = "It is not the case that John is a fool."

(23) John is no fool. = "There is no degree $d$ of being a fool such that John is a $d$ fool."

The paraphrase in 23, with the addition of nominal scale structure, produces a stronger statement than that of contradictory negation, in 22 , which says only that the subject is not a member of the class. I take this stronger statement to be the source contrary meaning as well as the greater informativeness of copular sentences with no-DPs compared to those with sentential negation. The proposed account of contrariety in predicate nominals therefore appeals to an underlying difference in the form of the two sentence types to explain why we get strengthened meaning in one case and not the other.

7. Arguments vs. predicates. It is now necessary to confront the question of how to account for the argument occurrences of no-DPs, where contrary meaning is unavailable. I propose that we analyze the argument and predicate occurrences of no uniformly, on the assumption that the dimensions of measurement differ for arguments and predicates: The meaning of no and its role in the structure remain constant.

In argument position, the dimension of measurement is quantitative, that of number or amount, the former for count nouns and the latter for mass nouns. This proposal is in line with a number of recent proposals that posit a cardinality operator as part of the meaning of quantifiers such as many, little and few (Hackl 2000/9, Heim 2006, Schwarzchild 2006 and Solt 2007/2104/16). Now, take Jespersen's original sentence No ordinary boy hates cricket, where no ordinary boy is a subject. Boy is a count noun, so the measurement function associated with the nominal ordinary boy in this position maps individuals onto their cardinality. The DP no ordinary boy indicates that there is no quantity of the class ordinary boy that has any degree of cardinality - in other words, the number of ordinary boys who hate cricket measures zero. 
8. Denials and strengthening without contrariety. Consider now the sentence in 24 . Examples such as 24 highlight the fact that the majority of ordinary noun meanings may not be readily associated with qualitative dimensions in the way that fool or the related idiot are. They are less suited for measurement as scalar predicates, and don't have any natural contrary terms. So, while it is possible to be a bit of an idiot or a total idiot, it is difficult to imagine a use for expressions like a bit of a chair or a total chair; similarly, it is possible to be an utter fool but not an utter dog - unless we use $d o g$ in a non-literal sense on which it can apply to humans, in which case the role of qualitative dimensions once again becomes clear (see e.g. Morzycki 2012).

It is nonetheless possible, in many of these cases that seem to lack qualitative meaning, to use adjectives like real, in sentences like "That is a real dog" or in exclamatives like "That is some dog!" and the existence of such examples seem to indicate that we are accessing dimensions of prototypicality in these cases, too. For example, it is possible to use a sentence like 24 in case you rate the prototypicality of a given instance of dog so low on the scale that you wish to question its membership in the set. Say we are talking about a Yorkshire Terrier, such a small and fragile breed of dog that we might use 19 to exaggerate its non-prototypicality, by saying it is so low on the scale it can hardly be called a member of the class.

(24) That is no dog.

Given the difference between nouns like fool and those like $d o g$, we might propose that the extent to which a noun makes qualitative dimensions available for quantification will determine their ability to productively combine with no in predicate position, but this would leave out an important use of these expressions in predicate positions, namely their use as denials. Sentence 24 can be used in case someone has previously mistaken a dog for a non-dog (so, for example, someone might say That's no dog-That's a woodchuck!). This use of predicate no-DPs shares with the copular sentence with sentential negation an inability interpreted with contrary meaning. In this connection, however, I would point out that even as denials the sentence with a no-DP predicate is stronger than a copular sentence with sentential negation. Consider the following scenario: We are looking at a picture of cityscape and I say, "That's Vienna!" You might disagree with me, and one way to do that is to say, "That's not Vienna!". But you might reply in another way-you might say, "That's no Vienna!" Now that response sets things on a different level, I believe, and as Frege (1892/1952) also recognized in his discussion of the sentence "Trieste is no Vienna"; If you say "That's no Vienna" you are saying that not only is the city in the picture not actually Vienna, but it's not even a city like Vienna. It could even imply that the person has it all wrong about what cultural capitals are like. This fact about denials with no-DPs speaks again to the role of prototypicality in the interpretation of predicative no-DPs, even in the absence of contrariety - because here Vienna stands for a prototypical cultural capital. For this reason I maintain that even in denials, the presence of no correlates with the measurement of qualitative dimensions that are part of the noun's meaning. In case the discourse already includes "x is an n", we can use " $x$ is no n" as a sweeping denial, stronger than what we achieve by the use of " $x$ is not an $n$ ". And I have argued that this difference, and the availability of contrary meaning for no-DP predicates, is attributable to the semantics of measurement in $n o$-DPs, meaning that is absent from sentences containing sentential negation.

\section{References}

Bartsch, Renate, and Theo Vennemann. 1973. Semantic structures: A study in the relation between syntax and semantics. Frankfurt: Athenäum Verlag. 
Collins, Chris and Paul Postal. 2014. Classical Neg-Raising: An Essay on the Syntax of Negation. Cambridge: MIT Press.

Frege, Gottlob. 1892/1952. On Concept and Object. In Translations from the Philosophical Writings of Gottlob Frege, P. Geach and M. Black (eds. and trans.), Oxford: Blackwell, pp. 42-55.

Hackl, Martin. 2000. Comparative quantifiers. Doctoral Dissertation, Massachusetts Institute of Technology.

- 2009. On the grammar and processing of proportional quantifiers: Most versus more than half. Natural Language Semantics 17. 63-98. DOI: 10.1007/s11050-008-9039-x

Heim, Irene. 2000. Degree operators and scope. Proceedings of the 10th Semantics and Linguistic Theory, eds. Brendan Jackson and Tanya Matthews, 40-64. Ithaca, NY: CLC Publications. DOI: http://dx.doi.org/10.3765/salt.v10i0.3102

- 2006. Little. Proceedings of the 16th Semantics and Linguistic Theory Conference, eds. Masayuki Gibson and Jonathan Howell, 35-58. Ithaca, NY: CLC Publications. DOI: http://dx.doi.org/10.3765/salt.v16i0.2941

Horn, Laurence R. 1989. A Natural History of Negation. Chicago: University of Chicago Press.

- 2014. The Singular Square: Contrariety and Double Negation from Aristotle to Homer. In J. Blochowiak, C. Grisot, S. Durrlemann-Tame, C. Laenzlinger (eds.), Papers dedicated to Jacques Moeschler, Genève. URL: www.unige.ch/lettres/linguistique/moeschler/Festschrift/Festschrift.php.

Horn, Laurence R. and Wansing, Heinrich, "Negation", The Stanford Encyclopedia of Philosophy (Winter 2016 Edition), Edward N. Zalta (ed.), forthcoming URL = https://plato.stanford.edu/archives/win2016/entries/negation/

Kennedy, Christopher. 2001. Polar opposition and the ontology of 'degrees'. Linguistics and Philosophy 24. 33-70. DOI: 10.1023/A:1005668525906

- 2007. Vagueness and grammar: The semantics of relative and absolute gradable adjectives. Linguistics and Philosophy 30. 1-45. DOI: 10.1007/s10988-006-9008-0

Ladusaw, W. (1992). "Expressing negation", in Semantics and Linguistic Theory (SALT) II, 237-259, Cornell University Press, Ithaca. DOI: http://dx.doi.org/10.3765/salt.v2i0.3030

Morzycki, Marcin. 2009. Degree modification of gradable nouns: size adjectives and adnominal degree morphemes. Natural Language Semantics 17. 175-203. DOI: 10.1007/s11050009-9045-7

- 2012. The several faces of adnominal degree modification. Proceedings of the 29th West Coast Conference on Formal Linguistics, eds. Jaehoon Choi, E. Alan Hogue, Jeffrey Punske, Deniz Tat, Jessamyn Schertz, and Alex Trueman, 187-95. Somerville, MA: Cascadilla.

Penka D. 2010. Oxford Studies in Theoretical Linguistics, vol. 32: Negative Indefinites. Oxford, UK: Oxford University Press.

Russell, Bertrand. 1903. The Principles of Mathematics. 2nd Ed. New York: W.W. Norton \& Company.

Sassoon, Galit Weidmann. 2007. Vagueness, gradability and typicality, a comprehensive semantic analysis. Doctoral Dissertation, Tel Aviv University.

—. 2010. Measurement theory in linguistics. Synthese 174. 151-80. DOI: 10.1007/s11229009-9687-5

— 2010. Adjectival vs. nominal categorization processes: The rule vs. similarity hypothesis. Belgium Journal of Linguistics 25. 104-47. 
Schwarzschild, Roger. 2006. The role of dimensions in the syntax of noun phrases. Syntax 9. 67110. DOI: $10.1111 /$ j.1467-9612.2006.00083.x

Solt, Stephanie. 2016. On measurement and quantification: the case of most and more than half. Language. 92: 1. 65-100. 10.1353/lan.2016.0016

- 2014b. Q-adjectives and the semantics of quantity. Journal of Semantics Published online February 3, 2014.

—. 2015. Measurement Scales in Natural Language. Language and Linguistics Compass 9:1. 14-32. DOI: $10.1111 / \mathrm{lnc} 3.12101$

Zanuttini R. 1991. Syntactic properties of sentential negation: a comparative study of Romance languages. $\mathrm{PhD}$ thesis, University of Pennsylvania.

—. 1997. Negation and Clausal Structure: A Comparative Study of Romance Languages. New York/Oxford, UK: Oxford Univ. Press

Zeijlstra, H. 2004. Sentential Negation and Negative Concord. PhD thesis, University of Amsterdam. 